\title{
A New Watershed Algorithm for Pothole Image Segmentation
}

\author{
Tutuk INDRIYANI ${ }^{1,2}$, Mohammad Imam UTOYO ${ }^{3}$, Riries RULANINGTYAS ${ }^{4 *}$ \\ ${ }^{1}$ Faculty of Sciences and Technology, University of Airlangga Surabaya, Indonesia \\ ${ }^{2}$ Department of Informatics, Institut Teknologi Adhi Tama Surabaya, Indonesia \\ tutuk@itats.ac.id \\ ${ }^{3}$ Department of Mathematics, University of Airlangga Surabaya, Indonesia \\ m.i.utoyo@fst.unair.ac.id \\ ${ }^{4}$ Department of Physics, University of Airlangga Surabaya, Indonesia \\ riries-r@fst.unair.ac.id (*Corresponding author)
}

\begin{abstract}
The road casualties caused by poor road conditions, especially potholed roads, amount to a high percentage of $13 \%$ per year in Asia. In order for the government to carry out repair works, they must know the surface area of the potholed road, the depth of the potholes, and the position of the potholes. In this paper, with the purpose of determining the surface area of the potholed road, segmentation was carried out first. The segmentation method used here is a new watershed algorithm. This algorithm includes six processes: smoothing, calculating the gradient value, automatic determination of minimum flooding value, combining the catchment basins, erasing the remaining watershed lines, and creating a watershed curve. The proposed algorithm is evaluated and compared with previously analysed watershed segmentation methods. This study shows that this algorithm is effective for reducing the effects of excessive segmentation. The proposed algorithm obtained a high accuracy of $95.34 \%$, which is higher than that of the existing watershed segmentation methods.
\end{abstract}

Keywords: Potholes road image, Segmentation, Watershed, A new watershed algorithm.

\section{Introduction}

Road accidents in 2019 in Asia occurred due to several reasons, such as $8 \%$ human negligence, $40 \%$ cornering road conditions, $9 \%$ slippery road conditions, $10 \%$ weather, sunken roads or puddles of asphalt on the surface $8 \%$, dark roads $12 \%$ and $13 \%$ potholes (Saad \& Tahar, 2019). Accidents caused by road potholes are second in line. Victims of accidents caused by damaged roads can sue for compensation from the Government (Fan et al., 2020). Therefore, the Government immediately repaired damaged roads, including potholes that could lead to traffic accidents. To carry out these repairs, the Government must know precisely the position, surface area, and depth of the potholes (Ouma \& Hahn, 2017); so far, the Government workers have done this manually.

To determine the surface area and depth of a potholed road, a preprocessing process is first carried out, and then the segmentation process is carried out (Yousaf et al., 2018). The segmentation method based on the similarity of pixels in one area is the watershed method (Kim, Nam \& Jang, 2017; Vrejoiu, 2020). The watershed method can divide the image into several different regions by depicting the image as a topographical relief (Omati \& Sahebi, 2018; Gamarra et al., 2019). This method is used for segmentation because it has the advantage of producing closed contoured regions and can show image details, but it has the disadvantage of over-segmentation (Zhang et al., 2019).

This paper puts forth a new watershed method, based on the watershed method that has been studied previously, which has an average accuracy below 92\% (Wenjuan et al., 2019; Challa et al., 2019; Girish et al., 2018), there is still oversegmentation (Girish et al., 2018; Patmonoaji et al., 2019) and gradient reconstruction using the Gaussian method (Fan, 2020; Sakly et al., 2020; (Lou et al., 2020), methods in finding the minimum flood in the catchment basin still use a threshold or are still manual (Zhang et al., 2019; Elyounsi et al., 2017; Ji et al., 2016). The watershed repair method in this study uses a new watershed algorithm. This algorithm is a novelty in this research. This watershed algorithm has six steps, the first step is filtering with the improve high boost filter method, the second step is to calculate the gradient value calculation, the third step to calculate the automatic determination of minimum flooding, the fourth step to combine the catchment basins with each other by giving the same label to two or more catchment basins that have a weight which is lower than the automatic minimum flood value, the fifth step to remove the remaining watershed lines and the last step to create a watershed curve. The use of this algorithm results in better accuracy, sensitivity, 
and specificity compared to previously studied watershed methods.

The new watershed algorithm aims to obtain high accuracy values in the segmentation process. The results of the segmentation process are used for interpreting the next process, which depends on the quality of the results of the segmentation process. The segmentation process that results in an accuracy value above $95 \%$ is a very important step (Yang et al., 2020). The segmentation method in this study is applied to the object image of the potholed road and evaluated by other watershed methods studied previously. This segmentation algorithm was also tested for other objects, namely apple, cortical bone, and bird images, to determine the accuracy of the proposed method. The remainder of this paper is structured as follows. Section 2 presents related work, section 3 describes the steps of the new watershed algorithm, section 4 sets forth the results of the algorithm process and section 5 puts forward the conclusion of this paper.

\section{Related Work}

Research on the segmentation of perforated road objects includes segmentation using the threshold algorithm (Sorandaru and Stanciu, 2019). To determine whether the road is defective or not defective using the watershed algorithm, the segmentation process produces an accuracy of $82 \%$ (Chung \& Khan, 2019). The location of potholes is detected with mobile mapping sensors (Wu et al., 2019), detection of potholes with 2D images using Fuzzy C-mean Clustering algorithm. The segmentation of the perforated road image using the graph cut method yields an accuracy of $81.4 \%$ (Vigneshwar \& Hema Kumar, 2017) for the classification of potholed roads using the Support vector machine method (Yousaf et al., 2018). Research that has developed watershed methods include image segmentation using the morphological watershed method (Wenjuan et al., 2019; Román et al., 2020; Chen et al., 2020). Image segmentation using the transformation watershed method (Yang et al., 2020; Xu et al., 2020). The segmentation results in the image using the morphological watershed and transformation watershed methods still contain noise. Segmentation using marker controlled watershed method (Girish et al., 2018; Marasigan Jr et al., 2019; Datta \& Chaki, 2020; Mon et al., 2018). The results of segmentation using the marker watershed method still have an average accuracy below $92 \%$. Image segmentation with gradient reconstruction watershed is presented in (Fan, 2020; Li et al., 2019). Image segmentation using an Improved watershed Algorithm is set forth in (Li et al., 2019; Tian et al., 2020; Tinnathi \& Sudhavani, 2020; Sivakumar \& Janakiraman, 2020 ) and preprocessing using a Gaussian filter resulted in an average accuracy of $83 \%$ (Zhou et al., 2019).

\section{Methodology}

The system design is shown in Figure 1.

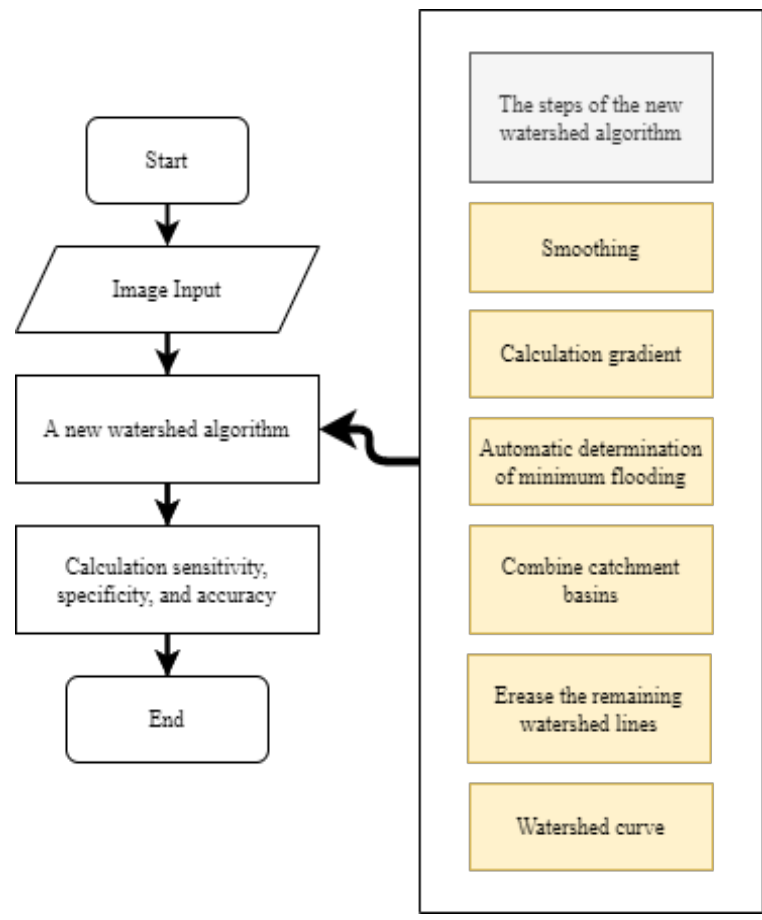

Figure 1. System design of a new watershed algorithm

The system design in this study consists of three processes, data input, development of the watershed method, and measurement of the segmentation results. The detailed explanation is as follows.

\subsection{The Proposed Algorithm Steps}

For the watershed algorithm to produce segmentation with reasonable accuracy, there are several steps that must be implemented.

\section{A. Smoothing}

In the first stage, the results of objects segmented by conventional watershed methods are carried out by smoothing with an improved high boost 
filter. The improved kernel used can be seen in Figure 2 and equation (1).

\begin{tabular}{|l|l|l|}
\hline-1 & -1 & -1 \\
\hline-1 & 9.5 & -1 \\
\hline-1 & -1 & -1 \\
\hline
\end{tabular}

Figure 2. Filtering process

$G(x, y)=-f(x, y-1)+9.5(x, y)-f(x, y+1)$

$-f(x-1, y-1)-f(x-1, y)-f(x-1, y+1)$

$-f(x+1, y-1)-f(x+1, y)-f(x+1, y+1)$

$G(x, y)$ is filtered image and $f(x, y)$ is defined as image input. Filtering using this kernel can obscure the watershed lines that are over-segmented, therefore it is easier to find the Gradient values compared to the low pass filter, high pass filter, and Gaussian filter (Indriyani, Utoyo \& Rulaningtyas, 2020).

\section{B. Gradient Value Calculation}

The second stage calculates the gradient employed for finding the lowest gradient value from the standard edge in the adjacent catchment basin. Its purpose is to identify the direction of terrain for each pixel in the image. The gradient values of the eight neighbors for each pixel will be determined by calculating the slope of the steepest hilltop area and the steepest downhill slope direction. Then, the gradient will be used as a weight to find the minimum flood from the edge, in equations (2), (3), and (4).

$$
\begin{aligned}
& G_{x}(x, y)=f(x+1, y+1)-f(x+1, y) \\
& +f(x, y+1)-f(x, y) \\
& G_{y}(x, y)=f(x, y+1)-f(x+1, y+1) \\
& +f(x, y)-f(x+1, y) \\
& G_{x, y}(x, y)=\sqrt{\left(G_{x}(x, y)\right)^{2}+\left(G_{y}(x, y)\right)^{2}}
\end{aligned}
$$

$(x, y)$ are the $x$ and $y$ coordinates, $f(x, y)$ is defined as image input, $G_{x}(x, y)$ is the gradient of $x$ direction, $G_{y}(x, y)$ is the gradient of $\mathrm{y}$ direction, and $G_{x, y}(x, y)$ is an image gradient.

\section{Automatic Determination of Minimum Flooding}

The third stage is to determine the minimum flood value automatically to find out the watershed image efficiently, which can describe the shape of a potholed road, in Figure 3.

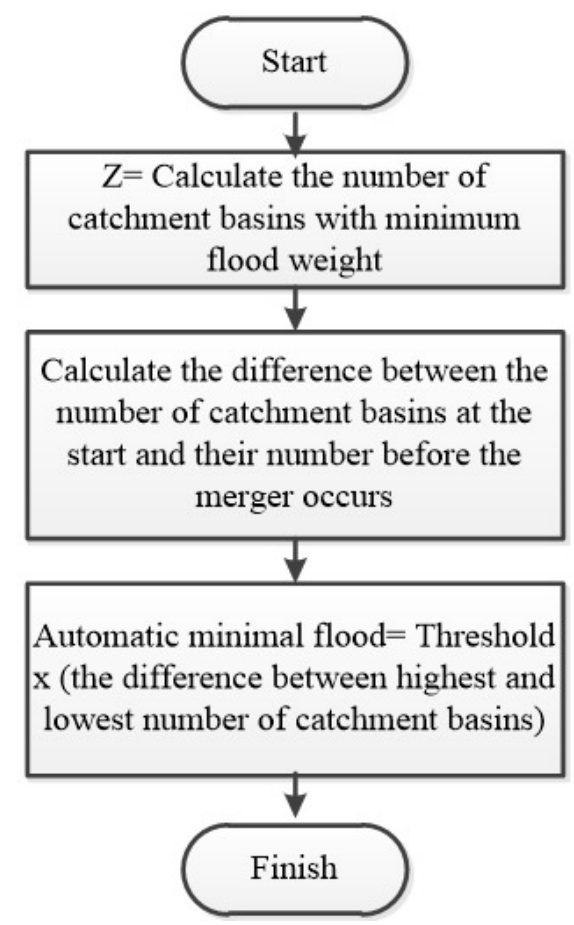

Figure 3. Automatic minimum flood

The first step is to calculate the number of catchment basins that have a minimum flood value. The second step is to calculate the difference between the number of catchment basins at the start and their number before the merger occurs. The third step is to find the number of reference catchment basins using the threshold limit multiplied by the result of the deduction from the highest number of catchment basins minus the lowest number of catchment basins. The threshold used is $90 \%$ based on trials. After obtaining the number of reference catchment basins, the automatic minimum flood will be obtained. In this case, the number of catchment basins is identical to that of the reference catchment basins. The automatic minimum flood that is accepted will be used as a reference for merging the catchment basins of each object, especially on potholes.

\section{Combine Catchment Basins}

The fourth stage is to combine the catchment basins with each other by giving the same label to 
two or more catchment basins that have a weight lower than the automatic minimum flood value, in Figure 4.

The fourth stage is to combine watersheds with each other by giving the same label to two or more watersheds that have a weight lower than the minimum automatic flood value, see Figure 4.

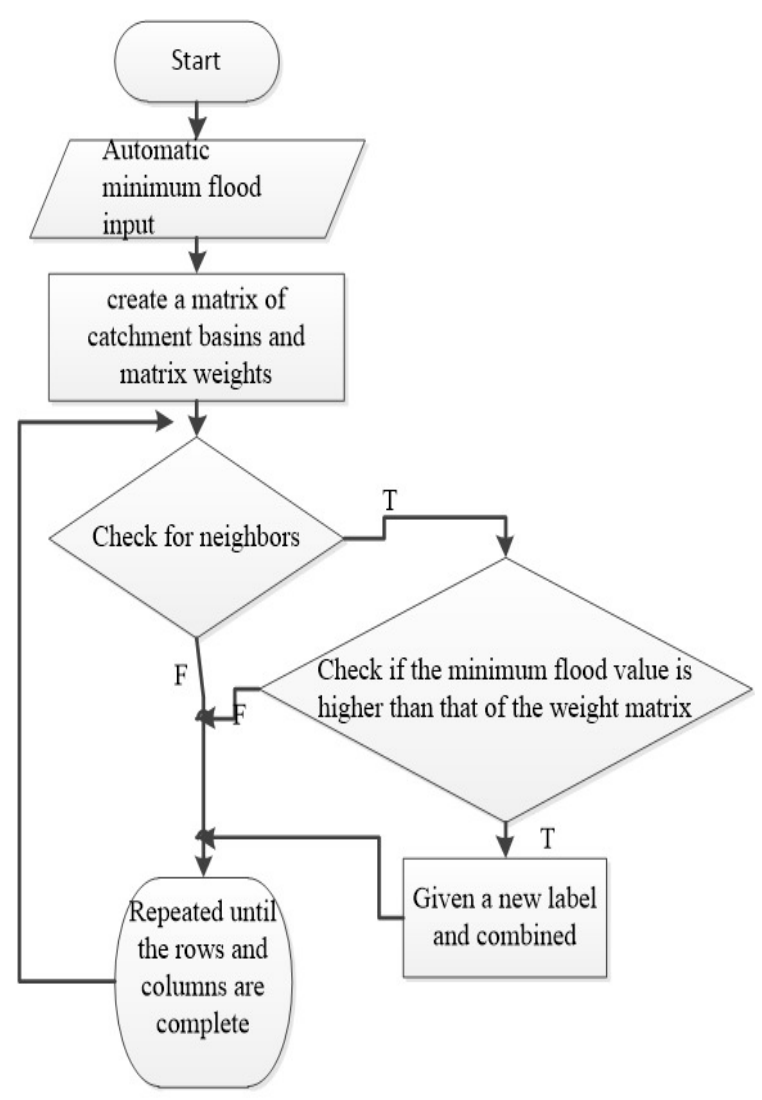

Figure 4. Flowchart combining catchment basins

Figure 4 can be described as follows. First, the minimum flood used for relabeling is input. The same labeling facilitates the merging process into one catchment basin with eight neighboring matrices. In the second step, two adjacent catchment basins are checked. Two neighboring catchment basins will be represented in $x$ and $y$ variables. After obtaining the $\mathrm{x}$ and $\mathrm{y}$ values, in in the third step, the existing possibilities are checked. The first possibility is whether the minimum flood value is higher than that of the weight matrix $(x, y)$ and the values of relabel $(x)$ and relabel $(y)$ are still determined to be equal to 0 , if the condition is correct, then it will be given a new label and catchment basins will be combined. The second possibility is if the four neighbor matrix is wrong, that is, four catchment basins are labeled the same, which means that there is only one catchment basin, and no merging is possible because it is already in a catchment basin. If the four possibilities are true, it means that there are four neighboring catchment basins. Such as, the four labels will be combined.

\section{E. Remove the Remaining Watershed Lines}

In this stage, the remaining upper and lower watersheds are removed because they have merged into one catchment basin, by checking whether the combined catchment basin still has a watershed line or not. If there are still watershed lines in the area that have joined, the watershed line is erased by using eight neighboring matrices. The first step is to look for label 0 on $f(x, y)$ the watershed image that has been combined with the catchment basin. The second step is to find eight neighbors at a point $f(x, y)$. The third step is to find four possibilities with regard to the eight neighbors, the 4 possibilities are the neighbor $f(x, y+1)$ is the same as the neighbor $f(x, y-1)$, the neighbor $f(x-1, y)$ is the same as the neighbor $f(x+1, y)$, neighbor $f(x-1, y-1)$ equals neighbor $f(x+1, y+1)$, neighbor $f(x+1, y-1)$ equals $f(x-1, y+1)$. The fourth step, if the probability is true, it can be ascertained that the watershed line is in the combined catchment basin.

\section{F. Creation of a Watershed Curve}

The sixth stage is to create a curve from the results of the new improved watershed with the aim of knowing the segmentation boundary connection according to the catchment basin concept, watershed line, and knowing the shape of the potholes object, see in Figure 5. The explanation in Figure 5 shows that the initial step is to determine the width of the image that has been processed from stage 1 to stage 5 . Then from the initial value to the end of the image width, a curve will be traced, if it has a label value 0 and if not then it will be repeated. This is done continuously to the end of the image width. 


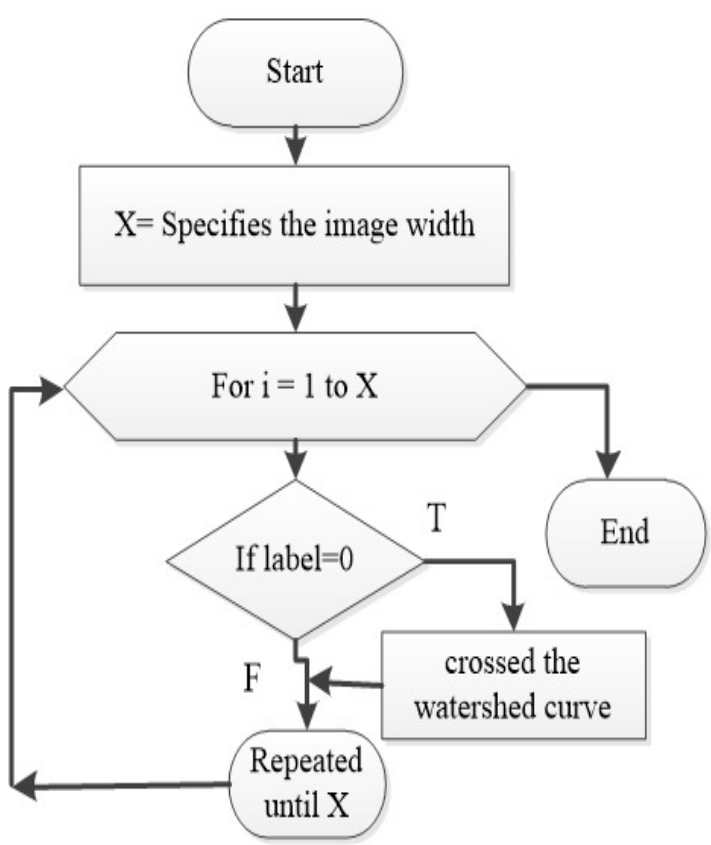

Figure 5. Flowchart of the catchment basin area through the watershed curve

\subsection{Specificity, Sensitivity, and Accuracy}

Measurement of segmentation results is done by calculating specificity, accuracy, and sensitivity. Accuracy is a measurement of how close the results of the system are to the true value. Specificity is the accuracy in identifying background areas. The sensitivity indicates how well the segmentation method identifies the foreground area. The calculation of sensitivity, specificity, and accuracy is expressed in equations (5) to (7) (Ruuska et al., 2018).

TP: This is the foreground and the system detects it as the foreground.

TN: This is the background and the system detects it as the background.

FP: This is the background and the system detects it as the foreground.

FN: This is the foreground and the system detects it as the background.

Accuracy $=\frac{(T P+T N)}{(T P+T N+F P+F N)} \cdot 100 \%$

Sensitivity $=\frac{T P}{(T P+F N)} \cdot 100 \%$

Specificity $=\frac{T N}{(F P+T N)} \cdot 100 \%$

\section{Result and Discussion}

\subsection{Data Set}

In this study, the experiment used 20 data sets of 2D potholed road images with a size of $256 \times 256$ pixels. This data set is primary data taken from potholes in Surabaya, Indonesia. For comparison purposes, in this study one also uses data sets that are different from the images of potholed roads, namely 20 pictures of apples, 20 images of cortical bones, and 20 pictures of birds. The three data sets are from Kaggle image dataset. These data sets were segmented with a new algorithm and the results were compared with those of previously investigated watershed methods. Watershed methods that have been studied previously are Morphological Watershed method (MW), Marker Watershed method (MrW), and Improve Watershed method (IW).

\subsection{Measurement of Four Methods on Potholes}

The results of the average segmentation measurement for 20 images tested with the watershed methods that have previously been studied in comparison with the new watershed algorithm are shown in Table 1.

Table 1. Measurement results from road potholes images

\begin{tabular}{|c|c|c|c|}
\hline \multirow{2}{*}{$\begin{array}{c}\text { Watershed } \\
\text { method }\end{array}$} & \multicolumn{3}{|c|}{ Average } \\
\cline { 2 - 4 } & Accuracy & Sensitivity & Specificity \\
\hline $\begin{array}{c}\text { MW (Chen et } \\
\text { al., 2020) }\end{array}$ & $80.70 \%$ & $76.00 \%$ & $86.26 \%$ \\
\hline $\begin{array}{c}\text { MrW } \\
\text { (Marasigan Jr } \\
\text { et al., 2019) }\end{array}$ & $78.41 \%$ & $88.58 \%$ & $69.96 \%$ \\
\hline $\begin{array}{c}\text { IW (Tian et al., } \\
\text { 2020) }\end{array}$ & $83.34 \%$ & $80.02 \%$ & $88.47 \%$ \\
\hline $\begin{array}{c}\text { The Proposed } \\
\text { Method }\end{array}$ & $95.34 \%$ & $90.04 \%$ & $97.37 \%$ \\
\hline
\end{tabular}

Based on the results of segmentation measurements in Table 1, the proposed watershed method produces the best specificity, accuracy, and sensitivity values compared with the morphological watershed method, marker-based watershed method, and improved watershed method. With regard to the average results obtained, for the proposed method accuracy has an 
average advantage of $14.31 \%$, sensitivity has an average advantage of $8.5 \%$ and specificity has an average advantage of $15.8 \%$. This is because this method proposes an algorithm for calculating the gradient value based on equation (3) to determine the minimum flood value as a reference and the search for the minimum flood value from data sets of 20 images is carried out automatically. Second, catchment basins are merged based on automatic minimum flood values to reduce the occurrence of over-segmentation. The marker watershed method has the lowest accuracy compared to the other three methods because it is difficult to adjust the assignment of markers if too many markers will result in over-segmentation and too few markers will combine different objects. The segmentation results of several watershed methods are shown in Figure 6.

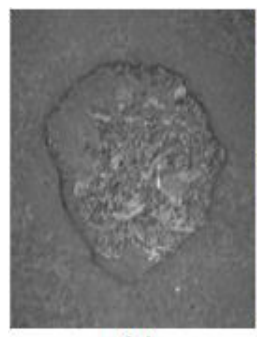

(a)

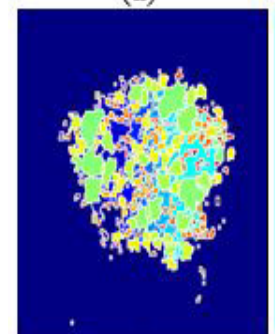

(d)

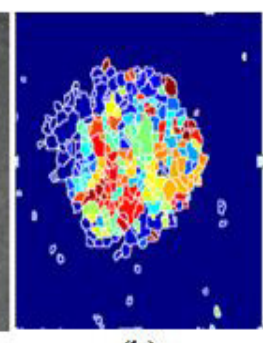

(b)

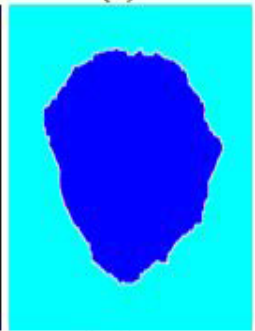

(e)
Figure 6. Example of experimental results for a potholed road image: (a) The original image; (b) Result of Chen et al. (2020); (c) Result of Marasigan Jr et al. (2019); (d) Result of Tian et al. (2020);

(e) Result of the proposed method

The proposed algorithm is shown in Figure (6) in plain view produces an image in which the road object with a hole and the background is clearly visible, and does not have noise also is not over segmented as compared to other segmentation methods. The Morphological, Marker-based and Improved watershed methods still include noise because the gradient search is still using conventional methods and the minimum flood search is done manually, while the objective algorithm is implemented automatically. The proposed algorithm produces a better image as it is obvious in Figure 6 by producing an average accuracy value of $95.34 \%$, a sensitivity value of $90.04 \%$, and a specificity value of $97.37 \%$.

\subsection{Four Measurement Methods on Three Compared Objects}

The results of the segmentation measurement for the three compared objects are shown in Tables (2)-(4) and the results for the related images are shown in Figures (7)-(9). The proposed algorithm produces the best sensitivity, accuracy, and specificity values compared to the three other methods that have been analyzed. The accuracy of the proposed algorithm for the three objects features an average advantage of $7.48 \%$, sensitivity has an average superiority of $8.55 \%$ and specificity has an average advantage of $7.66 \%$. No matter if the proposed algorithm is applied to segmentation with bright or clear image conditions and dim or less clear image conditions, it still produces better accuracy values compared to other methods.

Tabel 2. Measurement results from apple images

\begin{tabular}{|c|c|c|c|}
\hline \multirow{2}{*}{$\begin{array}{c}\text { Watershed } \\
\text { method }\end{array}$} & \multicolumn{3}{|c|}{ Average } \\
\cline { 2 - 4 } & Accuracy & Sensitivity & Specificity \\
\hline $\begin{array}{c}\text { MW (Chen et } \\
\text { al., 2020) }\end{array}$ & $94.62 \%$ & $81.87 \%$ & $88.14 \%$ \\
\hline $\begin{array}{c}\text { MrW } \\
\text { (Marasigan Jr } \\
\text { et al., 2019) }\end{array}$ & $83.44 \%$ & $80.18 \%$ & $82.50 \%$ \\
\hline $\begin{array}{c}\text { IW (Tian et al., } \\
\text { 2020) }\end{array}$ & $94.66 \%$ & $84.74 \%$ & $96.66 \%$ \\
\hline $\begin{array}{c}\text { The Proposed } \\
\text { Method }\end{array}$ & $97.73 \%$ & $91.17 \%$ & $98.89 \%$ \\
\hline
\end{tabular}

Tabel 3. Measurement results from cortical bone images

\begin{tabular}{|c|c|c|c|}
\hline \multirow{2}{*}{$\begin{array}{c}\text { Watershed } \\
\text { method }\end{array}$} & \multicolumn{3}{|c|}{ Average } \\
\cline { 2 - 4 } & Accuracy & Sensitivity & Specificity \\
\hline $\begin{array}{c}\text { MW (Chen et } \\
\text { al., 2020) }\end{array}$ & $84.83 \%$ & $84.21 \%$ & $81.34 \%$ \\
\hline $\begin{array}{c}\text { MrW } \\
\text { (Marasigan Jr } \\
\text { et al., 2019) }\end{array}$ & $83.15 \%$ & $82.52 \%$ & $81.76 \%$ \\
\hline $\begin{array}{c}\text { IW (Tian et al., } \\
\text { 2020) }\end{array}$ & $87.07 \%$ & $83.86 \%$ & $84.01 \%$ \\
\hline $\begin{array}{c}\text { The Proposed } \\
\text { Method }\end{array}$ & $95.21 \%$ & $96.93 \%$ & $92.19 \%$ \\
\hline
\end{tabular}


Tabel 4. Measurement results from bird images

\begin{tabular}{|c|c|c|c|}
\hline \multirow{2}{*}{$\begin{array}{c}\text { Watershed } \\
\text { method }\end{array}$} & \multicolumn{3}{|c|}{ Average } \\
\cline { 2 - 4 } & Accuracy & Sensitivity & Specificity \\
\hline $\begin{array}{c}\text { MW. (Chen et } \\
\text { al., 2020) }\end{array}$ & $91.81 \%$ & $94.90 \%$ & $89.02 \%$ \\
\hline $\begin{array}{c}\text { MrW } \\
\text { (Marasigan Jr } \\
\text { et al., 2019) }\end{array}$ & $85.98 \%$ & $90.23 \%$ & $86.74 \%$ \\
\hline $\begin{array}{c}\text { IW (Tian et al., } \\
\text { 2020) }\end{array}$ & $94.48 \%$ & $94.87 \%$ & $95.69 \%$ \\
\hline $\begin{array}{c}\text { The Proposed } \\
\text { Method }\end{array}$ & $97.09 \%$ & $96.77 \%$ & $96.64 \%$ \\
\hline
\end{tabular}

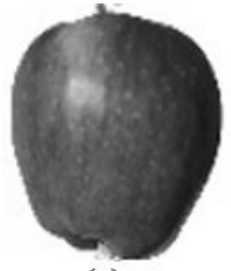

(a)

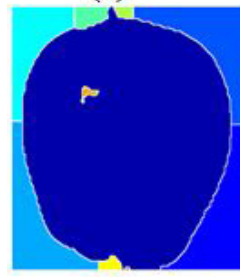

(d)

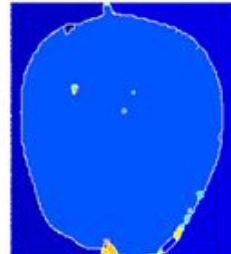

(b)

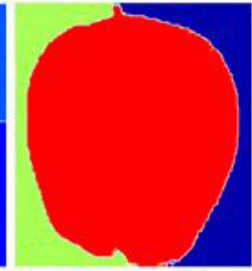

(e)

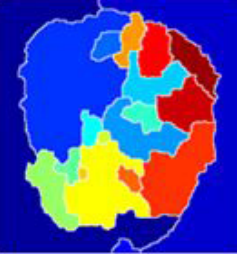

(c)
Figure 7. Example of experimental results - apple images: (a) The original image; (b) Result of Chen et al. (2020); (c) Result of Marasigan Jr et al. (2019) (d) Result of Tian et al. (2020): (e) Result of the proposed method

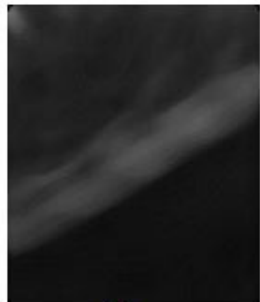

(a)

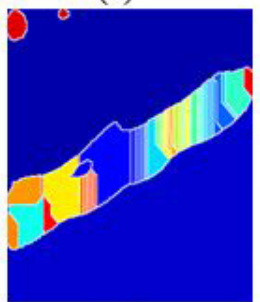

(d)

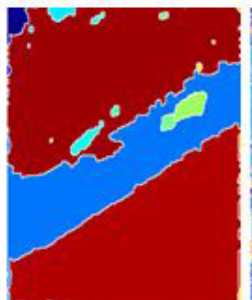

(b)

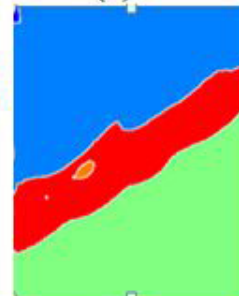

(e)

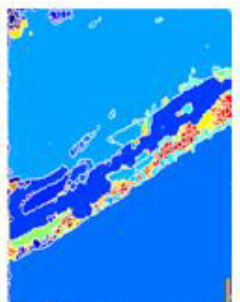

(c)
Figure 8. Example of experimental results - cortical bone images: (a) The original image; (b) Result of Chen et al. (2020); (c) Result of Marasigan Jr et al. (2019); (d) Result of Tian et al. (2020); (e) Result of the proposed method

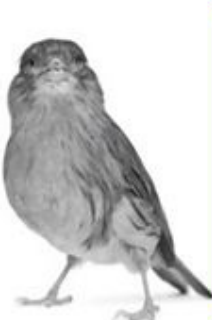

(a)

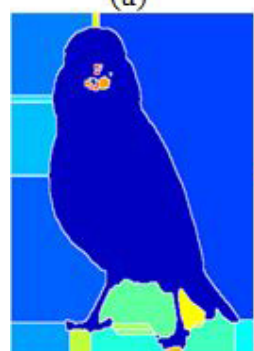

(d)

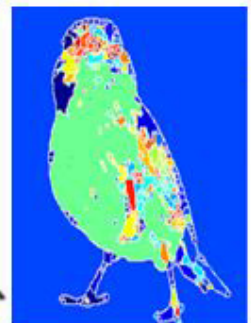

(b)

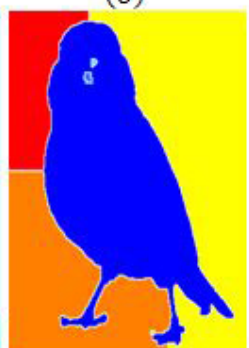

(e)

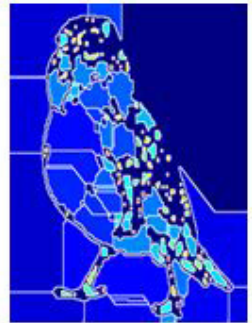

(c)
Figure 9. Example of experimental results - bird images: (a) The original image; (b) Result of Chen et al. (2020); (c) Result of Marasigan Jr et al. (2019);

(d) Result of Tian et al. (2020); (e) Result of the proposed method

\section{Conclusion}

The new watershed algorithm focused on filtering, calculating the gradient value in the image as a reference for automatically searching for the minimum flood value, merging one catchment basin with another, and removing the remaining watershed can produce good segmentation with high accuracy. The proposed algorithm, irrespective of being applied to segmentation with dim or unclear image objects and bright or clear image objects, still getting better accuracy, sensitivity, and specificity values compared to other watershed methods. The proposed algorithm can be applied to the next process, namely calculating the surface area of the potholed road object, which depends on the quality of the segmentation process.

\section{Acknowledgments}

The author would like to thank Airlangga University, the Promoter, and Co-Promoter for supporting this research. The author also wants to thank the LPDP BUDI-DN Indonesian Education Scholarship for funding this research. 


\section{REFERENCES}

Challa, A., Danda, S., Sagar, B. S. D. \& Najman, L. (2019). Watersheds for Semi-Supervised Classification, IEEE Signal Processing Letters, 17(3), 1-5. DOI: 10.1109/LSP.2019.2905155

Chen, Y., He, Y. I., Wang, J., Li, W. \& Xing, L., Gao, F \& Shi, G. (2020). Automated Cone Photoreceptor Cell Segmentation and Identification in Adaptive Optics Scanning Laser Ophthalmoscope Images Using Morphological Processing and Watershed Algorithm, IEEE Accsess, 8(1), 1-7.

Chung, T. D. \& Khan, A. (2019). Watershed-based Real-time Image Processing for Multi-Potholes Detection on Asphalt Road. In 9th IEEE International Conference on System Engineering and Technology (ICSET), (pp. 268-272).

Datta, S. \& Chaki, N. (2020). Dental x-ray Image Segmentation using Maker Based Watershed Technique in Neutrosophic Domain. In IEEE International Conference on Computer Science, Engineering and Applications, ICCSEA (pp. 1-5).

Elyounsi, A., Tlijani, H. \& Bouhlel, M. S. (2017). Combining top-hat, thresholding and watershed transformation for 3D Inverse Synthetic Aperture Radar Images segmentation. In 7th International Conference on Sciences of Electronics, Technologies of Information and Telecommunications, SETIT (pp. 466-471). DOI: 10.1109/SETIT.2016.7939915

Fan, H. (2020). Application of improved watershed image segmentation algorithm in post-processing of capacitive tomographic images. In IEEE International Conference on Artificial Intelligence and Information Systems (ICAIIS) Application (pp. 485-489).

Fan, R., Ozgunalp, U., Hosking, B., Liu, M. \& Pitas, I. (2020). Pothole Detection Based on Disparity Transformation and Road Surface Modeling, IEEE Transactions on Image Processing, 29, 897-908. DOI: 10.1109/TIP.2019.2933750

Gamarra, M., Zurek, E., Escalante, H. J., Hurtado, L. \& San-Juan-Vergara, H. (2019). Split and merge watershed: A two-step method for cell segmentation in fluorescence microscopy images, Biomedical Signal Processing and Control, 53(101575), 1-12. DOI: 10.1016/j.bspc.2019.101575

Girish, G. N., Kothari, A. R. \& Rajan, J. (2018). Marker controlled watershed transform for intraretinal cysts segmentation from optical coherence tomography B-scans, Pattern Recognition Letters, 139, 86-94. DOI: 10.1016/j.patrec.2017.12.019

Indriyani, T., Utoyo, I. \& Rulaningtyas, R. (2020). Comparison of image edge detection methods on potholes road images, Journal of Physics: Conference Series, 1613(1). DOI: 10.1088/17426596/1613/1/012067
Ji, X., Li, Y., Cheng, J., Yu, Y. \& Wang, M. (2016). Cell image segmentation based on an improved watershed algorithm. In Proceedings of 2015 8th International Congress on Image and Signal Processing, CISP 2015 (pp. 433-437). DOI: 10.1109/CISP.2015.7407919

Kim, J. J., Nam, J. \& Jang, I. G. (2018). Fully automated segmentation of a hip joint using the patient-specific optimal thresholding and watershed algorithm, Computer Methods and Programs in Biomedicine, 154,161-171. DOI: 10.1016/j.cmpb.2017.11.007

Li, J., Luo, W., Wang, Z. \& Fan, S. (2019). Early detection of decay on apples using hyperspectral reflectance imaging combining both principal component analysis and improved watershed segmentation method, Postharvest Biology and Technology, 149(12), 235-246. DOI: 10.1016/j. postharvbio.2018.12.007

Li, J., Zhang, R., Li, J., Wang, Z., Zhang, H. \& Zhan, B. \& Jiang, Y. (2019). Detection of early decayed oranges based on multispectral principal component image combining both bi-dimensional empirical mode decomposition and watershed segmentation method, Postharvest Biology and Technology, 158(4), 1-11.

Lou, S., Pagani, L., Zeng, W., Jiang, X. \& Scott, P. J. (2020). Watershed segmentation of topographical features on freeform surfaces and its application to additively manufactured surfaces, Precision Engineering, 63(21), 177-186. DOI: 10.1016/j. precisioneng.2020.02.005

Marasigan Jr, R., Festijo, E., Juanico, D. E. \& Medin, R. (2019). Improved Mangrove Crown Measurement from Airborne Lidar Data using Marker-controlled Watershed Algorithm-filtered Hamraz Technique. In 2019 1st International Conference on Electrical, Control and Instrumentation Engineering (ICECIE), (pp. 1-8).

Mon, K. L., Hlaing, S., Tin, M. M. \& Khin, M. M. (2018). Automatic Image Segmentation using Marker Controlled Watershed and Overlap Ratio Based Region Mergin. In 2018 IEEE 7th Global Conference on Consumer Electronics (GCCE), (pp. 564-565).

Omati, M. \& Sahebi, M. R. (2018). Change Detection of Polarimetric SAR Images Based on the Integration of Improved Watershed and MRF Segmentation Approaches, IEEE Journal of Selected Topics in Applied Earth Observations and Remote Sensing, 11(11), 4170-4179. DOI: 10.1109/ JSTARS.2018.2874517

Ouma, Y. O. \& Hahn, M. (2017). Pothole detection on asphalt pavements from 2D-colour pothole images using fuzzy c-means clustering and morphological reconstruction, Automation in Construction, 83(8), 196-211. DOI: 10.1016/j.autcon.2017.08.017 
Patmonoaji, A., Tsuji, K. \& Suekane, T. (2019) Porethroat characterization of unconsolidated porous media using watershed-segmentation algorithm, Power Technology, 362, 635-646.

Román, J. C., Legal-Ayala, H. \& Noguera, J. L. (2020). Applications of Multiscale Mathematical Morphology to Contrast Enhancement and Images Fusion. In 15th Iberian Conference on Information Systems and Technologies (CISTI), (pp. 1-7).

Ruuska, S., Hämäläinen, W., Kajava, S., Mughal, M., Matilainen, P. \& Mononen, J. (2018). Evaluation of the confusion matrix method in the validation of an automated system for measuring feeding behaviour of cattle, Behavioural Processes, 148, 56-62.

Saad, A. M. \& Tahar, K. N. (2019). Identification of rut and pothole by using multirotor unmanned aerial vehicle (UAV), Measurement: Journal of the International Measurement Confederation, 137, 647654. DOI: 10.1016/j.measurement.2019.01.093

Sakly, H., Said, M. \& Tagina, M. (2020). Evaluation of the active contour and topographic watershed segmentation "assessment of the systolic ejection fraction in the left ventricular for medical assistance in 5D short axis cine MRI", Heliyon, 6(11), 1-14. DOI: 10.1016/j.heliyon.2020.e05547

Sivakumar, V. \& Janakiraman, N. (2020). A novel method for segmenting brain tumor using modified watershed algorithm in MRI image with FPGA, BioSystems, 198(8), 1-13. DOI: 10.1016/j. biosystems.2020.104226

Sorandaru, C. \& Stanciu, I. R. (2019). Detecting Road Irregularities by Image Enhancements and Thresholding. In IEEE EUROCON 2019 - 18th International Conference on Smart Technologies (pp. 1-6). DOI: 10.1109/EUROCON.2019.8861790

Tian, X., Fan, S., Huang, W., Wang, Z. \& Li, J. (2020). Detection of early decay on citrus using hyperspectral transmittance imaging technology coupled with principal component analysis and improved watershed segmentation algorithms, Postharvest Biology and Technology, 161, 1-9. DOI: 10.1016/j. postharvbio.2019.111071

Tinnathi, S. \& Sudhavani, G. (2020). An efficient copy move forgery detection using adaptive watershed segmentation with AGSO and hybrid feature extraction, Journal of Visual Communication and Image Representation, 74(7), 1-19. DOI: 10.1016/j. jvcir.2020.102966
Vigneshwar, K. \& Hema Kumar, B. (2017). Detection and counting of pothole using image processing techniques. In 2016 IEEE International Conference on Computational Intelligence and Computing Research, ICCIC (pp. 1-4). DOI: 10.1109/ICCIC.2016.7919622

Vrejoiu, M. H. (2020). License plate segmentation in images based on per-block contrast analysis and CCA, Studies in Informatics and Control, 29(2), 189-203. DOI: $10.24846 /$ V29I2Y202005

Wenjuan, J., Dong, L. \& Fuyun, X. (2019). Brain CT Image Segmentation Based on Improved Watershed Algorithm. In 15th International Conference on Computational Intelligence and Security (CIS), (pp. 332-335). DOI: 10.1109/CIS.2019.00077

Wu, H., Yao, L., Xu, Z., Li, Y., Ao, X., Chen, Q., Li, Z. \& Meng, B. (2019). Road pothole extraction and safety evaluation by integration of point cloud and images derived from mobile mapping sensors, Advanced Engineering Informatics, 42. DOI: 10.1016/j.aei.2019.100936

Xu, H., Langer, M. \& Peyrin, F. (2020). Segmentation of Bone Vessels in 3D Micro-CT Images Using the Monogenic Signal Phase and Watershed. In IEEE 17th Internasional Symposium on Biomedical Imaging (ISBI), (pp. 741-744).

Yang, J., Kang, Z., Cheng, S., Yang, Z. \& Akwensi, P. H. (2020). An individual tree segmentation method based on watershed algorithm and 3D spatial distribution analysis from airborne LiDAR point clouds, IEEE Journal of Selected Topics in Applied Earth Observations and Remote Sensing, 13, 1055-1067.

Yousaf, M. H., Azhar, K., Murtaza, F. \& Hussain, F. (2018). Visual analysis of asphalt pavement for detection and localization of potholes, Advanced Engineering Informatics, 38(1), 527-537. DOI: 10.1016/j.aei.2018.09.002

Zhang, H., Tang, Z., Xie, Y., Gao, X. \& Chen, Q. (2019). A watershed segmentation algorithm based on an optimal marker for bubble size measurement, Measurement: Journal of the International Measurement Confederation, 138(1), 182-193. DOI: 10.1016/j.measurement.2019.02.005

Zhou, H., Song, K., Zhang, X., Gui, W. \& Qian, Q (2019). WAILS : Watershed Algorithm With ImageLevel Supervision for Weakly Supervised Semantic Segmentation, IEEE Accsess, 7, 42745-42756. 